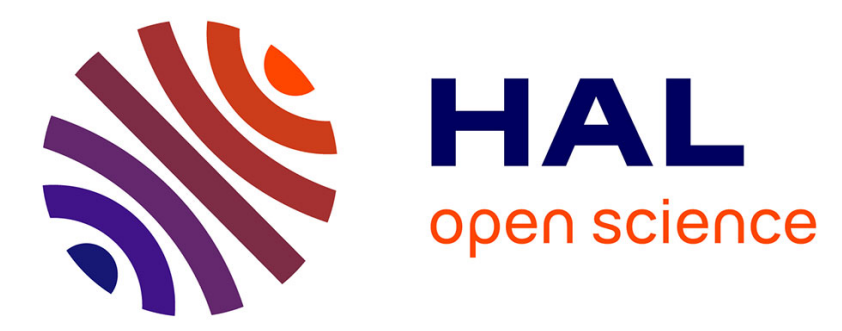

\title{
Determinants of AFM1 in breast milk in a selected group of Egyptian mothers
}

Nektaria Polychronaki, Paul C Turner, Hannu Mykkanen, Yunyun Gong, Hassan Amra, Mosaad Attia Abdel-Wahhab, Hani El-Nezami

\section{To cite this version:}

Nektaria Polychronaki, Paul C Turner, Hannu Mykkanen, Yunyun Gong, Hassan Amra, et al.. Determinants of AFM1 in breast milk in a selected group of Egyptian mothers. Food Additives and Contaminants, 2006, 23 (07), pp.700-708. 10.1080/02652030600627222 . hal-00577585

\section{HAL Id: hal-00577585 \\ https://hal.science/hal-00577585}

Submitted on 17 Mar 2011

HAL is a multi-disciplinary open access archive for the deposit and dissemination of scientific research documents, whether they are published or not. The documents may come from teaching and research institutions in France or abroad, or from public or private research centers.
L'archive ouverte pluridisciplinaire HAL, est destinée au dépôt et à la diffusion de documents scientifiques de niveau recherche, publiés ou non, émanant des établissements d'enseignement et de recherche français ou étrangers, des laboratoires publics ou privés. 


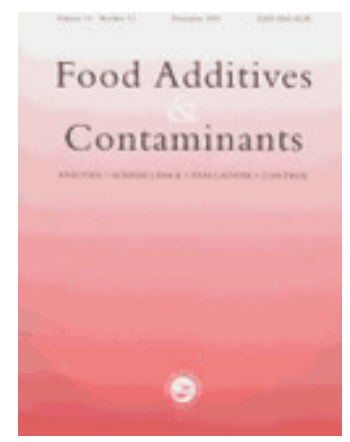

\section{Determinants of AFM1 in breast milk in a selected group of Egyptian mothers}

\begin{tabular}{|r|l|}
\hline Journal: & Food Additives and Contaminants \\
\hline Manuscript ID: & TFAC-2005-352.R1 \\
\hline Manuscript Type: & Original Research Paper \\
\hline Author: & O2-Feb-2006 \\
\hline & $\begin{array}{l}\text { Submitted by the } \\
\text { Turner, Paul; University of Leeds, Molecular Epidemiology Unit } \\
\text { Nutranen, Hannu; University of Kuopio, Department of Clinical } \\
\text { Nutrition } \\
\text { Gong, Yunyun; University of Leeds, Molecular Epidemiology Unit } \\
\text { Amra, Hassan; National Research Centre, Department of Food } \\
\text { Toxicology and Contaminants } \\
\text { Abdel-Wahhab, Mosaad; National Research Centre, Department of } \\
\text { Food Toxicology and Contaminants } \\
\text { El-Nezami, Hani; University of Kuopio, Department of Clinical } \\
\text { Nutrition }\end{array}$ \\
\hline Mdditives/Contaminants: & Aflatoxins \\
\hline Food Types: & Human milk \\
\hline &
\end{tabular}

\section{SCHOLARONE Manuscripts}




\section{Determinants of aflatoxin $\mathbf{M}_{1}$ in breast milk in a selected group of}

\section{Egyptian mothers}

3

4

5 Polychronaki Nektaria ${ }^{1,2}$, Turner C. Paul ${ }^{3}$, Mykkänen Hannu ${ }^{1}$, Gong Yunyun ${ }^{3}$, Amra Hassan $^{4}$,

6 Abdel-Wahhab Mosaad ${ }^{4}$, El-Nezami Hani ${ }^{1,2}$

7

$8 \quad{ }^{1}$ Department of Clinical Nutrition, University of Kuopio, Finland

$9 \quad{ }^{2}$ Food and Health Research Centre (ETTK), University of Kuopio, Finland

$10{ }^{3}$ Molecular Epidemiology Unit, Centre for Epidemiology and Biostatistics, Leeds Institute of

11 Genetics, Health and Therapeutics, University of Leeds, UK, LS2 9JT

$12{ }^{4}$ Department of Food Toxicology and Contaminants, National Research Centre, Dokki, Egypt 13 


\section{Abstract}

2 In Egypt there is a paucity of biomarker data on aflatoxin exposure. In this study we assessed

3 the level and frequency of breast milk $\mathrm{AFM}_{1}$ as a biomarker of maternal exposure. Breast milk

4 samples were collected from a selected group of 388 Egyptian lactating mothers of children

5 attending the New El-Qalyub Hospital, Qalyubiyah governorate, Egypt, during May-September

6 2003. Following aflatoxin extraction, $\mathrm{AFM}_{1}$ levels were assessed by HPLC with fluorescence

7 detection. Approximately $36 \%$ of mothers tested positive for $\mathrm{AFM}_{1}$ (median $13.5 \mathrm{pg} / \mathrm{ml}$, IQR

810.27 to 21.43 ). Non-working status $(p=0.018$, OR 2.87$)$, obesity $(p=0.004$, OR 3.01$)$, high

9 corn oil consumption $(\mathrm{p}=0.002$, OR 2.21), number of children $(>1)(\mathrm{p}=0.025$, OR 1.99), and

10 early lactation stage $(<1$ month) ( $\mathrm{p}=0.028$ OR 3.57), contributed to the occurrence of aflatoxin

11 in breast milk. $\mathrm{AFM}_{1}$ contamination of breast milk was frequent albeit at moderate levels.

12 Growth and development of the infant is rapid and thus it is possible that aflatoxin exposure

13 through breast milk has a significant health effect.

14

\section{Keywords}

16 Egypt, breast milk, aflatoxin $\mathrm{M}_{1}$, exposure, infants 


\section{Introduction}

2 Breast milk is considered to be the ideal food for the infant (Pronczuk et al. 2004; WHO 2003),

3 and the importance of breast-feeding for normal growth and development has become 4 increasingly recognized. However, in addition to its nutritionally and immunologically

5 beneficial components, human milk may contain trace amounts of a wide range of contaminants

6 following maternal dietary exposures (Jensen and Slorach 1991). In some less developed parts

7 of the world a family of highly toxic and carcinogenic naturally occurring compounds,

8 aflatoxins (AFs), have been observed in breast milk (Abdulrazzaq et al. 2003; El-Nezami et al.

9 1995; IARC 1993; Navas et al. 2005; Zarba et al. 1992). Aflatoxin $\mathrm{B}_{1}\left(\mathrm{AFB}_{1}\right)$, a potent liver carcinogen, is the most commonly occurring and carcinogenic of the aflatoxins, and is classified as a class 1A human carcinogen (IARC 1993). Maternal consumption of aflatoxin contaminated

12 food whilst breast feeding can result in the accumulation of aflatoxins and their metabolites in 13 breast milk. Approximately $95 \%$ of $\mathrm{AFB}_{1}$ metabolites excreted in milk are in the form of $\mathrm{AFM}_{1}$,

14 though $\mathrm{AFM}_{2}, \mathrm{AFG}_{1}$ and $\mathrm{AFB}_{1}$ are also reported (Abdulrazzaq et al. 2003; El-Nezami et al. 1995; Turconi et al. 2004; Zarba et al. 1992). IARC (1993) has classified $\mathrm{AFM}_{1}$ as a proven immune status of Ghanaian adults has been reportedly affected by aflatoxin exposure (Jiang et al. 2005).

In regions that are at high risk for aflatoxin contamination it is important to understand exposure patterns using aflatoxin biomarkers during pregnancy and early infancy to assess the health 1991), and then during early breast feeding $\mathrm{AFM}_{1}$ is likely to be the major aflatoxin ingested by 
1 the infant. In this respect it is important to note that $\mathrm{AFM}_{1}$ although less carcinogenic than

$2 \quad \mathrm{AFB}_{1}$, it is reportedly as cytotoxic (Neal et al. 1998), and is being consumed by infants that are 3 rapidly developing and thus highly susceptible to toxic insult. This study aims to assess 4 aflatoxin exposure in a selected group of nursing Egyptian mothers by measuring the level of $5 \mathrm{AFM}_{1}$ in breast milk. Aflatoxin exposure is known to occur in Egypt (El-Nezami et al. 2000; 6 Hifnawy et al. 2004; Selim et al. 1996), though there is limited biomarker data from this region. 7 It is possible that aflatoxin could contribute to the frequent growth faltering in this region, and 8 or play a role in the development of liver cancer. However, it is recognised that hepatits viruses 9 are the major contributors to liver cancer in Egypt (Angelico et al. 1997; Saeed et al. 1991). The 10 presence of aflatoxins in breast milk will indicate the frequency and level of both maternal and 11 to some extent early infant exposure. These data will serve as a baseline of exposure patterns 12 and levels, from which a longitudinal assessment of aflatoxin exposure and infant health can be 13 conducted.

\section{Materials and methods}

16 Study population

17 Breast milk samples were collected from 388 Egyptian mothers that agreed to participate in the 18 study (participation rate 95\%) during May-September 2003. The mothers were recruited by the 19 nurses of the New El-Qalyub Hospital, Qalyubiyah governorate, Egypt. Qalyubiyah governorate 20 is located in the eastern Nile region near the head of the Delta. The area is barred from the south 21 by Cairo and Giza governorates. The governorate is famous for its agricultural production of 22 maize, cotton, wheat, and several fruit and vegetables. In the Qalyubiyah governorate 23 approximately two thirds of the population lives in rural areas, and the humid and hot 24 environment promotes mould growth and aflatoxin production (El-Shewy 1987).

\section{Collection of dietary, socioeconomic, demographic and clinical data}

26 Intake of dietary sources of aflatoxins was assessed using a structured food frequency 27 questionnaire (FFQ) to record mother's usual intake over the last month before sample 28 collection. The FFQ was administered by interview conducted always by the same health centre 
1 nurse and thirty minutes were needed for completion. The FFQ focused on foods more likely to

2 contribute to dietary intake of aflatoxins and consisted of two components: a food list and a

3 frequency response section. The data on food use were expressed as frequencies ranging from several times a day to never. The groups of food included grain products (wheat bread, corn bread, pasta, rice, corn), milk and milk products (Romano cheese, feta cheese, cream), legumes (beans, lentils), meat (chicken, beef, lamb), fish, corn oil, cottonseed oil, dried fruits, and peanuts. These food groups include those likely to be aflatoxin contamination in Egypt (ElNezami et al. 2000; Hifnawy et al. 2004; Selim et al. 1996). Complete dietary data was received from all study subjects.

Socioeconomic data (working status, income, level of education), demographical data (place of residence, age), and clinical data (health status, miscarriages, medication) were recorded by interview while the anthropometrical data (mother's weight and height, baby's weight and height current and at delivery) were taken from the reports of the New El-Qalyub Hospital where the mothers were followed since the delivery. Child body weight was measured by nursing staff using a Tanita 1584, Precision weighing Balance, Bradford, MA (max weight 20 $\mathrm{kg}$, accuracy $50 \mathrm{~g}$ ). The socioeconomic status of the households was dichotomized in categories of either higher or lower (HSES/ LSES). HSES included families with one or both parents working and at least one work demanding higher education (teachers, nurses, government employees, police officers etc.), and LSES one or none of parents working and the work not demanding higher education (butcher, carpenter, tailor, salesman, conductor, driver, farmer etc.), respectively. For assessing children's growth status, the measured anthropometric values (baby's weight and height) were expressed as standard deviations (Z-scores) below or above the median value of the international reference population recommended by the National Centre of Health Statistics/World Health Organization (WHO) (WHO 1995). Weight for height Z-score (WHZ), weight for age Z-score (WAZ), and height for age Z-score (HAZ) below -2 reflects malnutrition, while a value below -3 severe malnutrition. 


\section{Breast milk aflatoxin extraction}

2 Breast milk was collected into a sterile plastic container by self-expression prior nursing the

3 baby. The sample was kept at $4{ }^{\circ} \mathrm{C}$ and frozen within one day at $-20{ }^{\circ} \mathrm{C}$ prior to extraction.

4 Extraction of aflatoxins from milk samples was modified from the method of El-Nezami et al

5 (1995). Briefly, $10 \mathrm{ml}$ breast milk samples were warmed to $37^{\circ} \mathrm{C}$ and were shaken to distribute

6 fat. For defatting, the samples were centrifuged $\left(3000 \mathrm{~g}, 15 \mathrm{~min}, 5^{\circ} \mathrm{C}\right)$ and filtered via glass

7 wool. To facilitate the passage through a C18 cartridge (Strata C18-E, 50 um, 70A,

8 Phenomenex, USA), the samples were diluted 1:1 with milli-Q water. The cartridge was pre-

9 activated with $10 \mathrm{ml}$ acetonitrile and then $10 \mathrm{ml}$ of water, prior to passage of diluted breast milk

10 at a flow rate of $3.5 \mathrm{ml} / \mathrm{min}$. The loaded cartridge was then washed with $10 \mathrm{ml}$ water, $10 \mathrm{ml}$

11 basic acetonitrile/ water (1\% ammonia, $10 \%$ acetonitrile) and $10 \mathrm{ml}$ acidic acetonitrile/water

12 (1\% acetic acid, $10 \%$ acetonitrile). $\mathrm{AFM}_{1}$ was eluted with $5 \mathrm{ml}$ acidic acetonitrile (1\% acetic

13 acid, $40 \%$ acetonitrile). $\mathrm{AFM}_{1}$ was extracted twice from the eluent with $2 \mathrm{ml}$ dichloromethane.

14 Following centrifugation $(3000 \mathrm{~g}, 15 \mathrm{~min})$ to separate the layers, the two dichloromethane

15 fractions were pooled and dried under nitrogen gas. The residue was dissolved in $0.7 \mathrm{ml}$ of

16 methanol.

17 HPLC analysis

18 Reverse phase HPLC (model LC-10ADvp solvent delivery system; model SIL-10Advp auto 19 injector, Shimadzu, Japan; ODS-5 C18 Brownlee reverse phase column (220 x $4.6 \mathrm{~mm}$, particle 20 size $5 \mu \mathrm{m}$ ) with a C18 guard column (Perkin Elmer, Norwalk, Conn.) was used to determine the 21 level of $\mathrm{AFM}_{1}$ in breast milk extracts. An isocratic system with water: methanol: acetonitrile $2266: 17: 17$, flow rate $1 \mathrm{ml} / \mathrm{min}$, oven temperature $40{ }^{\circ} \mathrm{C}$ and injection volume of $30 \mu \mathrm{l}$ were used. 23 Detection was by excitation at $360 \mathrm{~nm}$ and emission at $440 \mathrm{~nm}$ (Fluorescence-10A XL, 24 Shimadzu detector) (Figure 1). The concentrations of $\mathrm{AFM}_{1}$ in milk were estimated from a 25 standard curve 0.04-10 $\mathrm{ng} / \mathrm{ml}$ methanol, prepared from $\mathrm{AFM}_{1}$ in chloroform $(9.93 \mathrm{ug} / \mathrm{ml})$ 26 reference material RM 423 (LGC Promochem AB, Borås, Sweden). An $\mathrm{AFM}_{1}$ standard was 27 injected every 10 injections as a quality control, $\mathrm{AFM}_{1}$ was stored at $-20{ }^{\circ} \mathrm{C}$ in a sylilated vial 28 wrapped in aluminium foil. Since $\mathrm{AFM}_{1}$ is a possible carcinogen, care was exercised to avoid 
1 personal exposure and proper decontamination procedures with $10 \%$ sodium hypochlorite were

2 used. HPLC grade methanol, acetonitrile and dichloromethane were purchased from 3 Sigma/Aldrich Chemical Co. (Kemia Oy, Helsinki, Finland).

$5 \quad$ [Insert Figure 1 about here]

\section{$6 \quad$ Validation and repeatability of the measurements}

7 Validation and repeatability of the measurement of breast milk aflatoxin was carried out using 8 breast milk samples of Finnish mothers kindly provided by the Breast Milk Centre of Kuopio

9 University Hospital (Kuopio, Finland). These breast milk samples were extracted and analyzed by the method described above. $\mathrm{AFM}_{1}$ was not detected in these samples. For the recovery method of AOAC international (AOAC 1995). coefficient of variation.

The limit of detection was $0.06 \mathrm{ng} \mathrm{AFM}_{1} / \mathrm{ml}$ methanol or $4.2 \mathrm{pg} \mathrm{AFM}_{1} / \mathrm{ml}$ of breast milk based on a $10-\mathrm{ml}$ breast milk sample and reconstitution of extracts with $0.7 \mathrm{ml}$ of methanol, and was defined as the lowest concentration of $\mathrm{AFM}_{1}$ that could be reliably detected ( $>3: 1$ signal to noise ratio) and quantified $(\% \mathrm{CV}<20)$ for triplicate extractions. 
$1 \quad$ Ethical considerations

2 This study was approved by the Ethics Committee of the University of Kuopio and Kuopio

3 University Hospital in Finland and by the National Research Centre Ethical Committee in

4 Egypt. All subjects were made aware of the content of the study and if they agreed to

5 participate, a written informed consent was obtained.

6 Statistical analysis

7 SPSS 11.0 for windows was used in the statistical analysis of the data. AFM $_{1}$ values did not

8 follow normal distribution even after logarithmic transformation $(p=0.005$, Kolmogorov-

9 Smirnov normality test). Therefore, to identify possible associations between $\mathrm{AFM}_{1}$ levels and

10 related factors, the non-parametric Mann-Whitney U (or Kruskal-Wallis) test or Spearman

11 correlation were used for continues variables. The mothers were dichotomized depending on the

12 presence/absence of $\mathrm{AFM}_{1}$ in their breast milk, and chi-square test was used to associate the

13 presence of $\mathrm{AFM}_{1}$ in breast milk with categorical variables. Logistic regression models were

14 used to analyse the association of each potential factor and AFM1 presence/ absence. For the

15 FFQ data analysis, the food-consumption data were either regrouped into the two categories of

16 "daily consumption" and "weekly or monthly consumption" (the category "never" was included

17 to the "weekly or monthly consumption" category); or treated as continuous variable, i.e. the

18 reported frequencies of consumption were expressed as a number representing the frequency of

19 consumption. eg. 1/ month, 1 / fortnight, 1 / week or 3-4 times/ week equal $1 / 30$ or $0.03,1 / 15$ or

$200.06,1 / 7$ or $0.21,3.5 / 7$ or 0.5 respectively (Willet 1990). Missing data points in the results

21 presented reflect individuals for whom in one or more variable was missing for that analysis

22 being reported.

24 Results

\section{Descriptive characteristics and food consumption data}

26 Descriptive data of 388 mothers and their infants are presented in Tables 1 and 2. The median 27 age of the mothers was 25 years (range 15-47), most mothers (71.6\%) already had one or more 28 children, and $14 \%$ had previously had a miscarriage. Most households (76\%) belonged to LSES 
1 category and $89 \%$ of the mothers were not employed and were either at home or involved in

2 farming. Corn bread, wheat bread, corn oil, cotton seed oil and beans were used in a daily basis

3 by most of the mothers, but mothers belonging to the LSES category more frequently consumed 4 beans $(p=0.009)$, corn oil $(p=0.001)$, and cotton seed oil $(p=0.001)$ than mothers belonging to 5 the HSES category. Fifteen percent of the mothers were obese (BMI>30), and obese mothers 6 were consumers of corn oil more frequently than the non obese mothers ( 84 vs $67 \%, p=0.020$ ).

7 A few of mothers (6.2\%) reported a health problem associated with liver or intestine function,

8 while two percent of the mothers reported intake of medicines such as blood pressure reducing

9 tablets and anti-depressant tablets, or dietary supplements such as iron and calcium tablets.

11 [Insert Tables 1 and 2 about here]

13 There were 227 boys and 159 girls in the study (mean age 5.9 months: range 0.2- 33 months).

14 There were no reported illnesses within any of the infants. Anthropometric measures revealed 15 the prevalence rate for stunting (HAZ $\leq-2$ ) was $35.7 \%$, for being underweight (WAZ $\leq-2) 14.4 \%$, one parameter (extreme malnutrition). Median z-scores (IQR) for the infants were below zero for stunting and being underweight, but not for wasting (-1.49 (-2.63- 0.02), -0.45 (-1.47- 0.43) other age groups with lowest values in the 5- 8 month age group $(-2.25(-3.00--0.96)$, whereas WAZ scores were lowest in the oldest (>8 months) age group (-1.06 (-1.93- 0.13). WHZ was positively associated with age $(\mathrm{p}<0.001)$, however the median $\mathrm{Z}$-scores remained within normal 26 growth limits (-2 to 2 ) for all the age categories. 


\section{Breast milk AFM $_{1}$ levels and determining factors}

$3 \mathrm{AFM}_{1}$ was detected in the breast milk of 138 from the 388 mothers $(35.5 \%)$. The median level 4 of positives was $13.5 \mathrm{pg} / \mathrm{ml}$ (IQR 10.3 to 21.4). $\mathrm{AFM}_{1}$ in breast milk were detected 5 significantly more frequently $(\mathrm{p}=0.016)$ in mothers consuming corn oil on a daily basis $(39.7 \%)$ 6 compared to less frequent consumers (27.2\%) (Table 4). The frequency of having detectable $7 \mathrm{AFM}_{1}$ in breast milk varied greatly by duration of lactation, though there was no clear trend 8 with time. $\mathrm{AFM}_{1}$ was observed most frequently in breast milk in the first month of lactation (14/ $924,58 \%)$. The frequency of detection in the first month was significantly greater $(p=0.017)$ than that in subsequent months combined $(123 / 360,34 \%)$. Mothers who did not work were found to

11 have detectable $\mathrm{AFM}_{1}$ in breast milk more frequently (129/339, 38\%) than working mothers (7/ $1243,16 \%) . \mathrm{AFM}_{1}$ was detected more frequently $(25 / 51,49 \%)$ in obese women (BMI >30) 13 compared to those who were either overweight (BMI>25) (58/ 171, 34\%) and those whose BMI 14 was $<25(34 / 114,30 \%)(\mathrm{p}=0.031)$. In multivariable models, however BMI and corn oil 15 consumption were collinear to each other which restricted from being present in the same model. Therefore, separate models including either of these two factors were generated. When BMI was taken into consideration, mum's age, non working status, having more than one child, early lactation stage $\left(<1\right.$ month), and obesity appeared to be strong predictors of the $\mathrm{AFM}_{1}$

19 presence; non working mothers were 2.87 times more probable to be $\mathrm{AFM}_{1}$ positive than the working ones $(\mathrm{p}=0.018)$, having more than one child almost doubled the risk of being $\mathrm{AFM}_{1}$

21 positive ( $\mathrm{p}=0.025)$ and early lactation stage $(<1$ month) seemed to be a strong predictor of the 22 presence of $\mathrm{AFM}_{1}$ with an OR of $3.57(\mathrm{p}=0.028)$. BMI had a significant overall effect to the $23 \mathrm{AFM}_{1}$ presence $(\mathrm{p}=0.011)$. There was no difference in $\mathrm{AFM}_{1}$ frequency for overweight mothers 24 (BMI 25-30) compared to those with BMI $\leq 25(\mathrm{p}=0.57)$, though obese mothers $(\mathrm{BMI} \geq 30)$ had 25 three times greater risk of being positive to $\mathrm{AFM}_{1}$ than those with $\mathrm{BMI} \leq 25$ ( $\left.\mathrm{p}=0.004\right)$. In the 26 multivariate corn oil consumption model (excluding BMI), mothers with daily corn oil 27 consumption had 2.21 times greater risk of being $\mathrm{AFM}_{1}$ positive than the non frequent 
1 consumers $(\mathrm{p}=0.002)$. Replacing BMI with corn oil in the model didn't alter significantly the

2 strengths of the associations between the other variables and $\mathrm{AFM}_{1}$ presence.

3 Consumption of other grain products, milk and milk products, meat, fish, legumes, cotton seed

\section{Discussion}

10 Children are a highly susceptible population group for exposure to environmental toxicants for a

11 variety of reasons, including lower detoxification capacity, rapid growth, higher intakes of air,

12 food and water per kg body weight (Weaver et al. 1998) and therefore, early childhood exposure

13 to the carcinogenic aflatoxins may be critical determinants of later health effects. Exposures in

14 utero and through early infancy may additionally be important. $\mathrm{AFM}_{1}$ in breast milk is a marker

15 of dietary exposure of the mother to $\mathrm{AFB}_{1}$ and consequently aflatoxin exposure to the breastfeeding infant (Zarba et al. 1992). In this study 35.5\% of mothers were positive for breast milk

$17 \mathrm{AFM}_{1}$. The frequency is higher than that previously reported for this region (El-Shewy 1987), though this may reflect advances in analytical sensitivity. In our study the median level was

$1913.5 \mathrm{pg} / \mathrm{ml}$, range 5- 5000pg/ $\mathrm{ml}$ compared to that of El-Shewy et al (1987) who reported 22/ $200(11 \%)$ of samples were positive with a mean of those positive of $160 \mathrm{pg} / \mathrm{ml}$, range 120-200 $\mathrm{pg} / \mathrm{ml}$. The $\mathrm{AFM}_{1}$ levels in the breast milk of the Egyptian mothers are lower than the levels reported elsewhere. $\mathrm{AFM}_{1}$ was observed in breast milk from 129/ $140(92 \%)$ of samples in the United Arab Emirates with median level for positives of $560 \mathrm{pg} / \mathrm{ml}$ (range 5- $3400 \mathrm{pg} / \mathrm{ml}$ )

24 (Abdulrazzaq et al. 2003). El Nezami et al (El-Nezami et al. 1995) reported the median breast milk $\mathrm{AFM}_{1}$ levels in 11/ $73(15 \%)$ to be $71 \mathrm{pg} / \mathrm{ml}$ (range $\left.28-1031 \mathrm{pg} / \mathrm{ml}\right)$ in Victoria, Australia 26 and 5/ $11(45 \%)$ to be $664 \mathrm{pg} / \mathrm{ml}$ (range $39-1736 \mathrm{pg} / \mathrm{ml}$ ) in Thailand. In the Gambia, West 27 Africa all five breast milk samples analysed were positive for $\mathrm{AFM}_{1}$ with total milk values of 28 2100- 9200 pg reported (Zarba et al. 1992). 
1 Our data suggest that maternal aflatoxin exposure, and consequently infant exposure, is 2 occurring at moderate levels compared to some of the higher risk regions of Africa and south 3 east Asia. It is difficult to determine the average daily aflatoxin intake of the infant based on 4 breast milk exposure. Firstly, the maternal intake of aflatoxins will vary from day to day, and 5 thus breast milk levels will fluctuate. Aflatoxin or its metabolites may also be stored in fat 6 reserves though the levels and contribution, if any, to breast milk levels at a given stage of 7 lactation are not known. Secondly, the fat content and total milk volume will vary within a feed 8 and between feeds, and this will likely impact on the levels of aflatoxins observed. Thirdly, the 9 average volume an infant will consume in a day will vary. Despite these difficulties we can 10 make some estimates of aflatoxin intake in the 138 mothers with detectable $\mathrm{AFM}_{1}$ in breast 11 milk. Assuming average daily milk volume $500 \mathrm{ml}$, the average intake of $\mathrm{AFM}_{1}$ by the infant 12 can be estimated to be $6.75 \mathrm{ng}$ / day. Assuming $\mathrm{AFM}_{1}$ in human milk represents $0.09 \%$ to $0.43 \%$ 13 of dietary intake (Zarba et al. 1992), maternal intake is estimated at 1570 to $7500 \mathrm{ng} /$ day. The 14 calculated average daily intake by all women in two high risk regions for aflatoxin exposure 15 were $8 \mu \mathrm{g} \mathrm{AFB}_{1}$ in Zhuqing, China (Wang et al. 2001)and $15.7 \mu \mathrm{g}$ total aflatoxins in The 16 Gambia, West Africa (Groopman et al. 1992). Given that about $65 \%$ of mothers in our study 17 were not included in this estimate, the overall levels of these Egyptian mothers is modest by 18 comparison. Wean foods are introduced from about 4- 6 months which are likely to also be 19 contaminated if parental food is contaminated, thus the overall contribution to aflatoxin 20 exposure from breast milk will decline with time. However, breast feeding in Egypt, like other 21 African countries, often continues until infants are two years old, and thus over this extended 22 period the contribution made by breast milk may be important.

24 In Egypt the sources of aflatoxin exposure are less well defined than those of West Africa 25 (Turner et al., 2005). Non-working status, high BMI and/or corn oil consumption, number of 26 children $(>1)$, and early lactation stage contributed to the occurrence of aflatoxin in breast milk 27 reported in this study. The non-working mothers were not employed but mostly belonged in 28 small farmer communities, they were involved with farming and family work. In small farmer 
communities, the crops after being harvested are left to dry over plastic or synthetic sheets,

2 which may promote Aspergillus growth and toxin production (Turner et al. 2005). Most of these

3 crops are consumed locally by either the household or closer communities. High BMI seemed to

4 act as an indicator of the amount and type of food consumed including corn oil, with obese

5 mothers consuming corn oil more frequently than the non-obese mothers. Worldwide two of the

6 major sources of aflatoxin exposure are groundnuts and corn, thus corn oil is a potential source

7 of aflatoxin exposure in this region (El-Sayed et al. 2003; El-Tahan et al. 2000; Hifnawy et al.

8 2004). The fact that obese mothers had higher $\mathrm{AFM}_{1}$ levels than the non-obese, possibly reflects

9 the frequency of consumption of corn oil, and thus weakened contribution of corn oil to breast milk $\mathrm{AFM}_{1}$ level in our analysis when both factors were considered. and mobilization of aflatoxins. of aflatoxin-albumin adducts have been associated with growth faltering in Beninese infants

24 (Gong et al., 2002; 2004). In common with many developing countries (Shrimpton et al. 2001) underweight, based on WHO criteria (WHO 1995). In this study we do not have biomarkers of

27 infant aflatoxin exposure, though the modest maternal breast milk levels of AFM1 would 
1 Beninese study. In our follow up longitudinal study we will assess infant biomarkers of

2 aflatoxin exposure which may be more informative in this respect.

3 In Egypt, weaning foods are those consumed by the rest of the household, and the fact that 4 mothers are exposed ensures the exposure of their children. Overall the breast milk 5 contamination with aflatoxin is moderate, compared to some high exposure regions. However,

6 for genotoxic carcinogenic substances such as aflatoxins, a threshold value below which the risk 7 value for human health is equal to zero does not exist. The Joint FAO/WHO Expert Committee 8 on Food Additives (JEFCA) does not establish a tolerable daily intake (TDI), but strongly 9 recommends that the level of aflatoxin should be as low as possible. Therefore, the toxicological 10 significance of the presence of aflatoxin in maternal milk should not be overlooked. 11 Consequently, a reduction of mother's exposure to aflatoxins and thus, a reduction of children's 12 exposure through the breast milk is desirable. Reductions in aflatoxin exposure can be 13 envisaged by several approaches. Where the source of contamination is clearly defined such as 14 in Guinea, West Africa, post harvest changes to drying and storage of at risk foods is effective 15 (Turner et al. 2005). Where dietary sources are less well defined such as in Egypt, reduction in 16 uptake of aflatoxins may be achieved by dietary modulation, eg. with chlorophyllin (Egner et al. 17 2001) or probiotics (El-Nezami et al. in press). 


\section{References}

2 Abdulrazzaq YM, Osman N, Ibrahim A. 2002. Fetal exposure to aflatoxins in the United Arab 3 Emirates. Ann Trop Paediatr. 22: 3-9.

4

5 Abdulrazzaq YM, Osman N, Yousif ZM, Al-Falahi S. 2003. Aflatoxin M1 in breast-milk of

6 UAE women. Ann Trop Paediatr. 23: 173-179.

8 Angelico M and Renganathan E and Gandin C and Fathy M and Profili MC and Refai W et al.

9 1997. Chronic liver disease in the Alexandria governorate, Egypt: contribution of

10 schistosomiasis and hepatitis virus infections. J Hepatol. 26: 236-243.

AOAC. 1995. Aflatoxins M1 and M2 in fluid milk (Scott PM, ed) In: Natural Toxins. Arlington,

13 VA: Association of Official Analytical Chemists. 49: 34-35.

Natl Acad Sci U S A. 98: 14601-14606.

El-Nezami H, Ma J, Polychronaki N, Zhu H, Ling W, Salminen EK et al.. Probiotic supplementation reduced biomarker for increased risk of liver cancer in young Chinese males

El-Nezami H, Mykkänen H, Kankaanpaa P, Suomalainen T, Salminen S, Ahokas J. 2000.

Ability of a mixture of lactobacillus and propionibacterium to influence the faecal aflatoxin content in healthy Egyptian volunteers: a pilot clinical study. Bioscience Microflora. 19: 41-45. breast milk samples from Victoria, Australia and Thailand. Food Chem Toxicol. 33: 173-179. 
2 El-Sayed AM, Soher EA, Sahab AF. 2003. Occurrence of certain mycotoxins in corn and corn-

3 based products and thermostability of fumonisin B1 during processing. Nahrung. 47: 222-225.

4

5 El-Shewy EA. 1987. Some Toxicological Studies on contaminated breast milk by aflatoxins

$6[\mathrm{PhD}$ thesis]. Egypt, Faculty of Medicine: Zagazig University, Benha Branch

7

8 El-Tahan FH, El-Tahan MH, Shebl MA. 2000. Occurrence of aflatoxins in cereal grains from

9 four Egyptian governorates. Nahrung. 44: 279-280.

10

11 Gong Y and Cardwell K and Hounsa A and Egal S and Turner PC and Hall AJ et al. 2002.

12 Dietary aflatoxin exposure and impaired growth in young children from Benin and Togo: cross

13 sectional study. BMJ. 325: 20-21.

14

15 Gong Y and Hounsa A and Egal S and Turner PC and Sutcliffe AE and Hall AJ et al. 2004.

16 Postweaning exposure to aflatoxin results in impaired child growth: a longitudinal study in

17 Benin, West Africa. Environ Health Perspect. 112: 1334-1338.

18

19 Groopman JD and Hall AJ and Whittle H and Hudson GJ and Wogan GN and Montesano R et

20 al. 1992. Molecular dosimetry of aflatoxin-N7-guanine in human urine obtained in The Gambia,

21 West Africa. Cancer Epidemiol Biomarkers Prev. 1: 221-227.

22

23 Hifnawy MS and Mangoud AM and Eissa MH and Nor Edin E and Mostafa Y and Abouel-

24 Magd Y et al. 2004. The role of aflatoxin-contaminated food materials and HCV in developing

25 hepatocellular carcinoma in Al-Sharkia Governorate, Egypt. J Egypt Soc Parasitol. 34: 479-488.

27 IARC. 1993. Some naturally occurring substances - food items and constituents, heterocyclic

28 aromatic amines and mycotoxins. IARC Monogr Eval Carcinog Risks Hum 27. 
2 Jensen AA and Slorach SA. 1991. Chemical contaminants into human milk. Florida, United

3 States.

4

5 Jiang Y, Jolly PE, Ellis WO, Wang JS, Phillips TD, Williams JH. 2005. Aflatoxin B1 albumin

6 adduct levels and cellular immune status in Ghanaians. Int Immunol. 17: 807-814.

8 Lawrence RA. 1999. Breastfeeding: a guide for the medical profession. 5th ed. St.Louis,

9 London, Mosby.

10

11 Lunn PG. 2000. The impact of infection and nutrition on gut function and growth in childhood.

12 Proc Nutr Soc. 59: 147-154.

14 Navas SA, Sabino M, Rodriguez-Amaya DB. 2005. Aflatoxin M(1) and ochratoxin A in

15 a human milk bank in the city of Sao Paulo, Brazil. Food Addit Contam. 22: 457-462.

16

17 Neal GE, Eaton DL, Judah DJ, Verma A. 1998. Metabolism and toxicity of aflatoxins M1 and

18 B1 in human-derived in vitro systems. Toxicol Appl Pharmacol. 151: 152-158.

Pronczuk J, Moy G, Vallenas C. 2004. Breast milk: an optimal food. Environ Health Perspect. 112: $722-723$

Saeed AA and Al-Admawi AM and Al-Rasheed A and Fairclough D and Bacchus R and Ring C

24 et al. 1991. Hepatitis C virus infection in Egyptian volunteer blood donors in Riyadh. Lancet.

$25 \quad 338: 459-460$.

27 Selim MI, Popendorf W, Ibrahim MS, El-Sharkawy S, El-Kashory ES. 1996. Aflatoxin B1 in common Egyptian foods. J AOAC Int. 79: 1124-1129. 
2 Shrimpton R, Victora CG, de Onis M, Lima RC, Blossner M, Clugston G. 2001. Worldwide

3 timing of growth faltering: implications for nutritional interventions. Pediatrics. 107: 75.

4

5 Turconi G and Guarcello M and Livieri C and Comizzoli S and Maccarini L and Castellazzi

6 AM et al. 2004. Evaluation of xenobiotics in human milk and ingestion by the newborn-an

7 epidemiological survey in Lombardy (Northern Italy). Eur J Nutr. 43: 191-197.

8

9 Turner PC, Moore SE, Hall AJ, Prentice AM, Wild CP. 2003. Modification of immune function

10 through exposure to dietary aflatoxin in Gambian children. Environ Health Perspect. 111: 217-

11220.

12

13 Turner PC, Sylla A, Gong YY, Diallo MS, Sutcliffe AE, Hall AJ et al. 2005. Reduction in

14 exposure to carcinogenic aflatoxins by postharvest intervention measures in west Africa: a

15 community-based intervention study. Lancet. 365: 1950-1956.

16

17 Wang JS and Huang T and Su J and Liang F and Wei Z and Liang Y et al. 2001. Hepatocellular

18 carcinoma and aflatoxin exposure in Zhuqing Village, Fusui County, People's Republic of

19 China. Cancer Epidemiol Biomarkers Prev. 10: 143-146.

20

21 Weaver VM, Buckley TJ, Groopman JD. 1998. Approaches to environmental exposure

22 assessment in children. Environ Health Perspect. 106 Suppl 3: 827-832.

23

24 WHO. 1995. Physical status: the use and interpretation of anthropometry. Geneva 854.

25

26 WHO. 2003. Global strategy for infant and young child feeding. Geneva

27 
1 Wild CP, Rasheed FN, Jawla MF, Hall AJ, Jansen LA, Montesano R. 1991. In-utero exposure to

2 aflatoxin in west Africa. Lancet. 337: 1602.

3

4 Willet W. 1990. Nutritional Epidemiology. New York Oxford University Press 15.

5

6 Zarba A, Wild CP, Hall AJ, Montesano R, Hudson GJ, Groopman JD. 1992. Aflatoxin M1 in

7 human breast milk from The Gambia, west Africa, quantified by combined monoclonal

8 antibody immunoaffinity chromatography and HPLC. Carcinogenesis. 13: 891-894.

9 
1 Table 1. Descriptive maternal data.

\begin{tabular}{|c|c|c|c|c|}
\hline Mother & & $\%$ (Number) & Median (IQR) & Range \\
\hline \multirow[t]{2}{*}{$\overline{\mathrm{AFM}} \mathbf{M}_{1}(\mathrm{pg} / \mathrm{ml})$} & negative & $64 \%(250)$ & & \\
\hline & positive & $36 \%(138)$ & $13.5(10.3-21.4)^{*}$ & $5.6-5131 *$ \\
\hline \multicolumn{2}{|l|}{ Lactation stage** } & & $5(2-8)$ & $0.2-33.0$ \\
\hline \multicolumn{2}{|l|}{ Age (years) } & $100(381)$ & $25(22-30)$ & $15-47$ \\
\hline \multirow[t]{3}{*}{ Number of miscarriages $^{\#}$} & Total & $100(383)$ & - & - \\
\hline & 0 & $86 \quad(331)$ & & \\
\hline & $1-3$ & $14 \quad(52)$ & & \\
\hline \multirow[t]{3}{*}{ Number of children ${ }^{\# \#}$} & Total & $100(384)$ & - & - \\
\hline & 1 & $28.4(109)$ & & \\
\hline & $2-7$ & $71.6(275)$ & & \\
\hline \multirow[t]{5}{*}{ Maternal BMI } & Total & $100(336)$ & $26.0(24.0-28.5)$ & $15.8-68.9$ \\
\hline & $<20$ & $2.4 \quad(8)$ & & \\
\hline & $20-<25$ & $31.5(106)$ & & \\
\hline & $25-<30$ & $50.9(171)$ & & \\
\hline & $>30 \quad>>$ & $15.2 \quad(51)$ & & \\
\hline \multirow[t]{3}{*}{ Employed (\%) } & Total & $100(382)$ & - & - \\
\hline & unemployed & $89 \quad(339)$ & & \\
\hline & employed & $11(43)$ & & \\
\hline \multirow[t]{3}{*}{ Socioeconomic status } & Total & $100(384)$ & - & - \\
\hline & $\operatorname{LSES}^{\S}$ & $76.3(293)$ & & \\
\hline & HSES $^{\S}$ & $23.7(91)$ & & \\
\hline
\end{tabular}

2 *for positive samples, **number of months that mother has been breastfeeding index child

3 " prior to index child, ${ }^{\#}$ including index child

$4{ }^{\S}$ (LSES) Low socioeconomic status, (HSES) High socioeconomic status 5 
1 Table 2. Descriptive infant data.

\begin{tabular}{|c|c|c|c|c|}
\hline Child & & $\%$ (Number) & Median (IQR) & Range \\
\hline \multirow[t]{2}{*}{ sex } & boys & $\begin{array}{ll}58 & \text { (227) }\end{array}$ & - & \\
\hline & girls & (159) & & \\
\hline age (months) & & & $5(2$ to 8$)$ & 0.2 to 33.0 \\
\hline \multirow[t]{4}{*}{ HAZ } & & $100 \quad(322)$ & $-1.49(-2.63$ to 0.02$)$ & -4.2 to 2.9 \\
\hline & $>-2$ & $64.2 \quad(207)$ & & \\
\hline & -3 to -2 & $17.4 \quad(56)$ & & \\
\hline & $\leq-3$ & $18.3 \quad(59)$ & & \\
\hline \multirow[t]{4}{*}{ WAZ } & & $100 \quad(375)$ & $-0.45(-1.47$ to 0.43$)$ & -4.5 to 4.6 \\
\hline & $>-2$ & $85.6 \quad(321)$ & & \\
\hline & -3 to -2 & $9.3 \quad(35)$ & & \\
\hline & $\leq-3$ & $5.1 \quad(19)$ & & \\
\hline \multirow[t]{4}{*}{ WHZ } & & $100 \quad(351)$ & $0.82(0.17$ to 1.66$)$ & -2.3 to 4.8 \\
\hline & $>-2$ & $99.4(349)$ & & \\
\hline & -3 to -2 & $0.6 \quad(2)$ & & \\
\hline & $\leq-3$ & $0 \quad(0)$ & & \\
\hline
\end{tabular}

$2 \overline{\overline{\text { Malnutrition status is based on World Health Organization Guidelines. }}}$

3 Z score less than -2 for HAZ (stunting), WAZ (being underweight) or WHZ (wasting) is defined

4 as malnutrition, while less than -3 as severe malnutrition. 
1 Table 3. Relationship between infant age and HAZ, WAZ and WHZ.

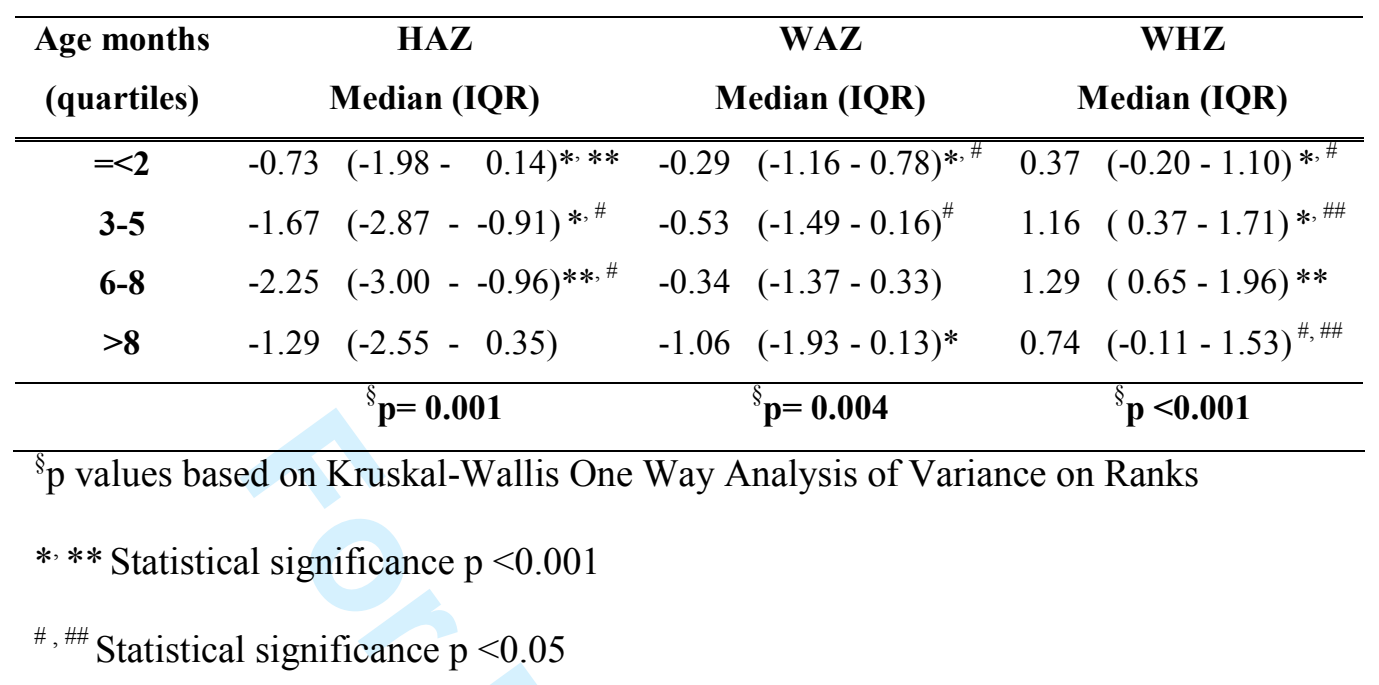


1 Table 4. Factors significantly associated with the presence of $\mathrm{AFM}_{1}$ in breast milk.

\begin{tabular}{|c|c|c|c|c|c|c|}
\hline \multirow[t]{3}{*}{ Mothers (n) } & \multirow{3}{*}{$\begin{array}{c}\mathrm{AFM}_{1} \\
\text { positive } \\
\mathbf{n}(\%)\end{array}$} & \multirow{3}{*}{$\begin{array}{c}\text { Univariate } \\
\text { Unadjusted } \\
\text { p-values }\end{array}$} & \multicolumn{4}{|c|}{ Multivariate model } \\
\hline & & & \multicolumn{2}{|c|}{ All variables } & \multicolumn{2}{|c|}{ Without corn oil } \\
\hline & & & $\begin{array}{l}\text { Adjusted } \\
\text { p-values }\end{array}$ & $\begin{array}{c}\text { Adjusted OR } \\
(95 \% \mathrm{CI})\end{array}$ & $\begin{array}{l}\text { Adjusted } \\
\text { p-values }\end{array}$ & $\begin{array}{c}\text { Adjusted OR } \\
(95 \% \mathrm{CI})\end{array}$ \\
\hline Mother's age & - & 0.460 & 0.014 & $0.94(0.89-0.99)$ & 0.014 & $0.94(0.89-0.99)$ \\
\hline $\begin{array}{l}\text { Working status } \\
\text { non-working (339) } \\
\text { working }(43)\end{array}$ & $\begin{array}{c}129(38.1) \\
7(16.3)\end{array}$ & 0.005 & 0.016 & $2.99(1.22-7.01)$ & 0.018 & $2.87(1.2-6.87)$ \\
\hline $\begin{array}{l}\text { Number of children } \\
2-7(275) \\
1(109)\end{array}$ & $\begin{array}{l}105(38.2) \\
32(29.4)\end{array}$ & 0.104 & 0.039 & $1.89(1.03-3.46)$ & 0.025 & $1.99(1.09-3.64)$ \\
\hline $\begin{array}{l}\text { Lactation stage } \\
<1 \text { month (24) } \\
\geq 1 \text { months }(360)\end{array}$ & $\begin{array}{c}14(58.3) \\
123(34.2)\end{array}$ & 0.017 & 0.016 & $4.25(1.30-13.86$ & 0.028 & $3.57(1.15-1.09)$ \\
\hline $\begin{array}{l}\text { Corn oil consumption } \\
\text { daily (262) } \\
\text { weekly/ monthly (125) }\end{array}$ & $\begin{array}{l}104(39.7) \\
34(27.2)\end{array}$ & 0.016 & 0.172 & $1.47(0.84-2.57)$ & - & - \\
\hline $\begin{array}{l}\text { BMI } \\
\leq 25 \text { (not overweight) } \\
(114)\end{array}$ & $34(30)$ & 0.031 & 0.019 & & 0.011 & \\
\hline 25-30 (overweight) (171) & $58(34)$ & & 0.684 & $1.12(0.65-1.92)$ & 0.578 & $1.16(0.68-1.99)$ \\
\hline$\geq 30$ (obese) (51) & $25(49)$ & & 0.008 & 2.79 (1.31-5.91) & 0.004 & $3.01(1.43-6.33)$ \\
\hline
\end{tabular}

2 


\section{Figure legends}

2

3 Figure 1. HPLC chromatograms of $\mathbf{A F M}_{1}$. Mobile phase $\mathrm{H}_{2} \mathrm{O}: \mathrm{CH}_{3} \mathrm{OH}: \mathrm{CH}_{3} \mathrm{CN}, 66: 17: 17$;

4 flow rate: $1 \mathrm{ml} / \mathrm{min}$; column: ODS-5 C18 220 x 4.6, fluorescence detection (ex. $360 \mathrm{~nm}$, em. 440

$5 \mathrm{~nm})$. (a) $\mathrm{AFM}_{1}$ extracted from an Egyptian breast milk sample (1004 pg/ ml breast milk or 14

$6 \mathrm{ng} / \mathrm{ml}$ methanol); (b) $\mathrm{AFM}_{1}$ standard $10 \mathrm{ng} / \mathrm{ml}$ methanol; (c) $\mathrm{AFM}_{1}$ extracted from spiked water $7 \quad(250 \mathrm{pg} / \mathrm{ml}$ water or $5 \mathrm{ng} / \mathrm{ml}$ methanol). 


\section{$1 \quad$ Figure 1}

2 (a)

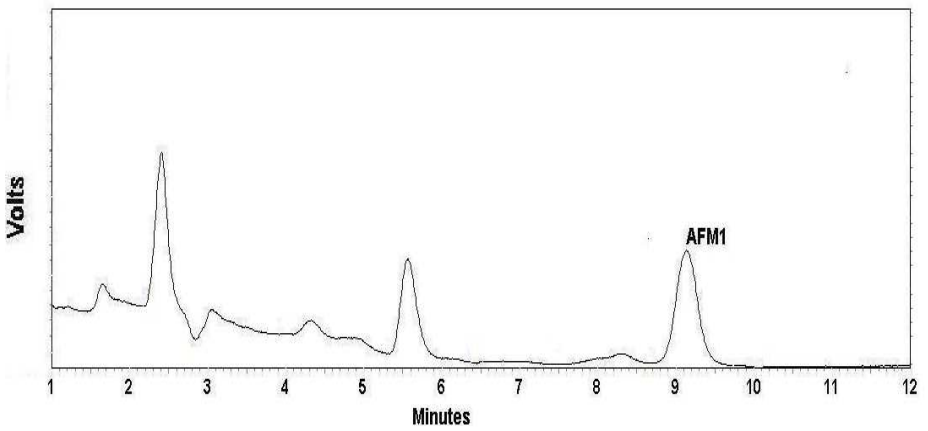

5 (b)

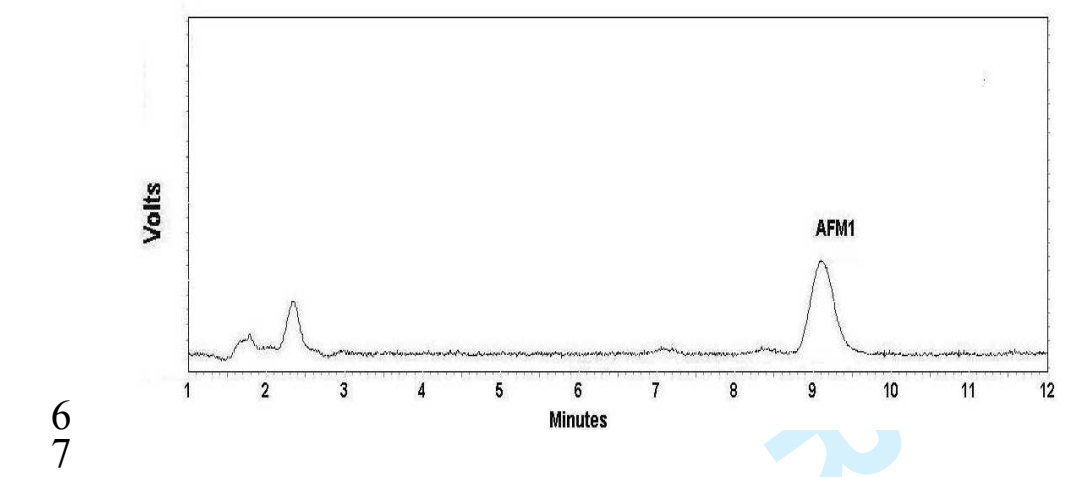

8 (c)

9

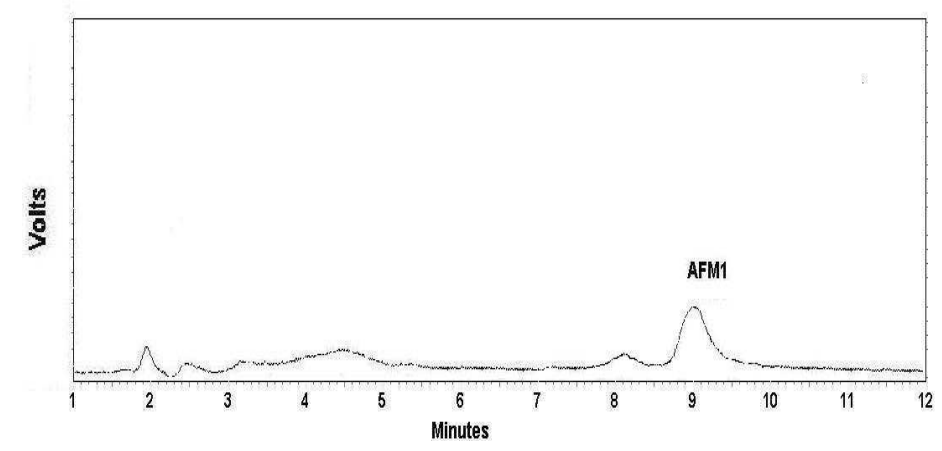

